NASA-CR-205248

Reprinted from

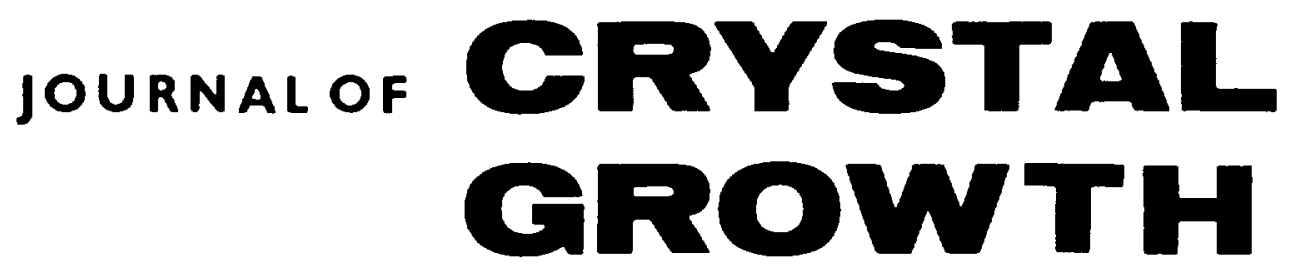

Journal of Crystal Growth $173(1997) 427 \quad 439$

\title{
Removal of oxygen from electronic materials by vapor-phase processes
}

\author{
Witold Palosz ${ }^{1, *}$ \\ NASA, Marshall Space Flight Center, Space Sciences Lahoratory, ES75, Huntsille, Alabama 35812, USA \\ Received 22 July 1996; accepted 27 September 1996
}

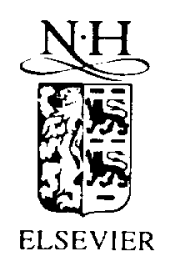




\section{Journal of Crystal Growth}

EDITORIAL BOARD

M SCHIEBER (Principal Editor) Graduate School of Appl. Sci. Hebrew I/niversity, Jerusalem 91904, Israel Telefax: +972-2-566 3878

R. KERN

CRMC $^{2}$. CNRS, Campus Luminy, Case 913

F-13288 Marselle Cedex 9 , France

Telefax $+33-91-4-418916$
The Fredy and Nadine Herrmann

\author{
R.S. FEIGELSON \\ Ctr. Materials Res. 105 McCullough Bldg. \\ Stanford Univ., Stanford, CA 94305-4045, USA \\ Telefax: + 1-415-7233044 \\ T. NISHINAGA \\ Dept. Electron. Eng, Univ. of Tokyo \\ 7-3-1, Hongo, Bunkyo-ku, Tokyo 113, Japan \\ Telefax: + 81-3-5684-3974
}

\section{ASSOCIATE EDITORS}

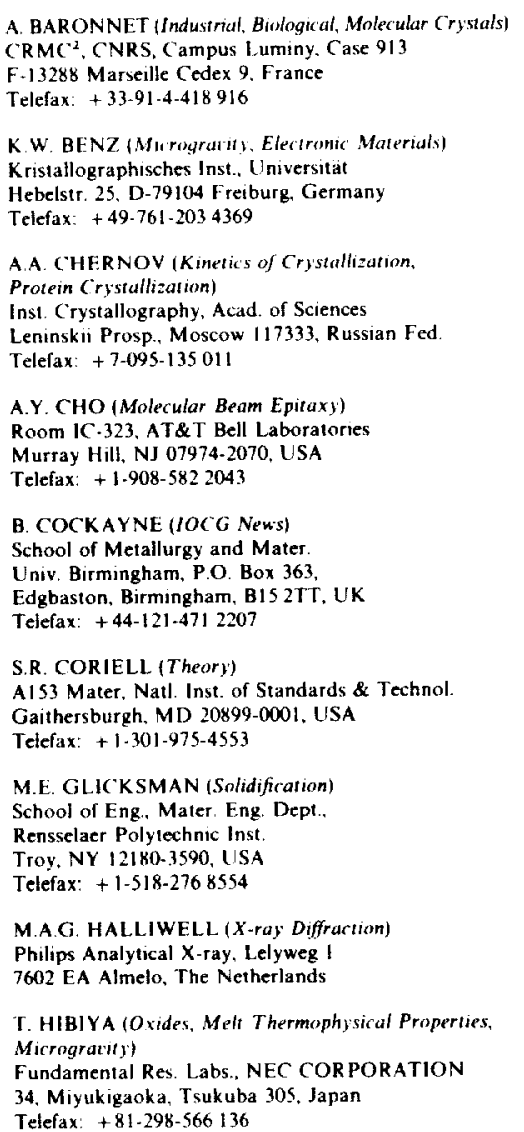

\author{
H. KOMATSU (Proteins Molecular Crystallization. \\ Growth from Solutions) \\ Inst. Mater. Res.. Tohoku Univ. \\ Katahira 2-1-1, Sendai 980, Japan \\ Telefax: $+81-22-2152011$ \\ T.F. KUECH (Thin Films and Electronic \\ and Optical Devices) \\ Dept. Chem. Eng., Univ. Wisconsin-Madison \\ Madison, WI 53706 , USA \\ Telefax: + 1-608-265378 \\ A McPHERSON (Protein Growth) \\ Dept. Biochemistry, Univ of Catifornia \\ Riverside, CA 92521, ISA \\ Telefax: + 1-909-787 3790 \\ P.A MORRIS HOTSENPILLER (Electrooptical \\ Crystals, Book Review's, Oxide Thin Filmst \\ E.I. du Pont de Nemours \& Co., Exp. Station \\ Wilmington, DE 19888-0358, USA \\ Telefax: + 1-302-6951664 \\ J.B. MULLIN (Semiconductors) \\ EMC. "The Hoo", Brockhill Road \\ West Malvem. Worcs., WR 14 4DL, UK \\ Telefax: + 44-1684-575591 \\ R.W. ROUSSEAU (Solution Growth, \\ Industrial Crystallization) \\ School of Chem. Eng., Georgia Inst. of Technol. \\ Atlanta, GA 30332-0100, USA \\ Telefax: + 1-404-894 2866 \\ K. SATO (Biocrystallization and \\ Organic (rystals) \\ Fac. Appl. Biol. Sci., Hiroshima Univ. \\ Higashi-Hiroshima 724, Japan \\ Telefax: + 81-824-227062 \\ L.F. SCHNEEMEYER (Superconductivity, \\ Oxides, Nolel Materials) \\ Room 1A-363, AT\&T Bell Labs. \\ Murray Hill, NJ 07974-2070, USA \\ Telefax: + 1-908-582 2521 \\ DW SHAW (Semiconductors, Epitaxy, Devices) \\ Texas Instruments Inc PO Box 655936. MS 147 \\ Dallas, TX 75265 , USA \\ Dallas, TX 75265, USA
Telefax: $+1-214-9957785$ \\ I. SUNAGAWA (Minerals) \\ 3-54-2 Kashiwa-cho, Tachik awa-shi \\ Tokyo 190, Japan \\ Telefax: + 81-425-35 3637
}

K. NAK AJIMA (Liquid and Vapor Phase Epitaxy) Integrated Mater Lab Fujitsu Labs. Ltd Morinosato-Wakamiya 10-1, Atsugi 243-01, Japan Morinosato-Wakamiya 10-1
Telefax: + 81.462-48 3473

H. OHNO (Epitaxy)

Research Inst. of Electrical Commun.

Tohoku Univ., Sendai 98077 , Japan

Telefax: + 81-22-2175553

K. PLOOG (Molecular Beam Epitaxy)

Paul-Drude-inst. fuir Festkörperelektronik

Hausvogteiplatz 5 7, D-10117 Berlin, Germany

Telefax + 49-30-203 77201

F. ROSENBERGER (Protein Crystallization,

Fluid Dynamics)

Center for Microgravity and Materials Research

Univ. Alabama, Huntsville, AL 35899, USA

Telefax: + 1-205-8906791
G. VAN TENDELOO (Electron Microscopy,

Fullerenes, Superconductivity)

University of Antwerp, RUCA

Groenenborgerlaan 171, B-2020 Antwerp-Belgium

Groenenborgerlaan 171,

A.F. WITT (Semiconductor Crystals)

Dept. of Metall. \& Mater. Sci.. Massachusetts Inst. of Technol., Cambridge, MA 02139, USA

Telefax: + 1-617-2535827

A. ZANGWILL (Theory (Epitaxy)

School of Physics, Georgia Inst. of Technol

Atlanta, GA 30332, USA

Telefax: + 1-404-8949958
D.T.J. HURLE

H.H. Wills Phys. Lab., Univ. Bristol

Tyndall Avenue

Bristol BS8 ITL. UK

G.B. STRINGFELLOW

Dept Mater. Sci., 304 EMRO, Univ. of Utah

Salt Lake City, UT 84112, USA

Telefax: +1-801-58! 4816
Scope of the Journal

Experimental and theoretical contributions are invited in the following fields: Theory of nucleation and growth, molecular kinetics and transport phenomena, crystallization in viscous media such as polymers and glasses. Crystal growth of metals, minerals, semicunductors magnetics, inorkanic organic and biological substances in bulk or as

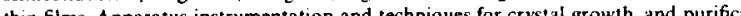
tion methods. Characterization of single crystals by physical and chemical methods

\section{Abstracted/Indexed in:}

Aluminium Industry Abstracts; Chemical Abstracts; Current Contents; Physical. Chemical and Earth Sciences; El Compendex Plus; Engineered Materials Absiracts, Engineering Index; INSPEC; Metals Abstracts.

\section{Subscription Information 1997}

Volumes 170-181 of Journal of Crystal Growth (ISSN 0022-0248) are scheduled for publication. (Frequency: semimonthly.) Prices are available from the publishers upon request. Subscriptions are accepted on a prepaid basis only. Issues are sent by SAL (Surface Air Lifted) mail wherever this service is available. Airmail rates are available upon request. Please address all enquiries regarding orders and subscriptions to:

Elsevier Science, B.V., Order Futfilment Department P.O. Box 211, 1000 AE Amsterdam. The Netherlands Tel: +31204853642 , Fax: +31204853598

Claims for issues not received should be made within six months of our publication (mailing) date.

US mailing notice Journal of Crystal Growth (ISSN 0022-0248) is published senumonthly by Fisevier Science B. V. Molenwerf 1, P.O. Box 211, 1000 AE Amsterdam. The Netherlands Anmul sub NY 11431.

US postmasters: Send address changes to Journal of Crystal Growth. Publications Expediting. Inc., 200 Meacham A venue, EImont NY 11003 . Airfreight and mailing in the USA by Publications Expediting.

(O) The paper used in this publication meets the requrements of ANSI/NISO Z39.48-1992 (Permanence of Paper)

PRINTED IN THE NETHERLANDS 


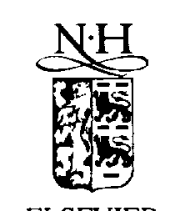

ELSEVIER

\title{
Removal of oxygen from electronic materials by vapor-phase processes
}

\author{
Witold Palosz ${ }^{1, *}$ \\ NASA. Marshall Space Flight Center. Space Sciences Lahoraton, ES75, Huntstille, Alabama 35812. USA
}

Received 22 July 1996; accepted 27 September 1996

\begin{abstract}
Thermochemical analyses of equilibrium partial pressures over oxides with and without the presence of the respective element condensed phase, and hydrogen, chalcogens, hydrogen chalcogenides, and graphite are presented. Theoretical calculations are supplemented with experimental results on the rate of decomposition and/or sublimation/vaporization of the oxides under dynamic vacuum, and on the rate of reaction with hydrogen, graphite, and chalcogens. Procedures of removal of a number of oxides under different conditions are discussed.
\end{abstract}

\section{Introduction}

Electronic compounds are usually synthesized from high-purity elements typically of $\mathrm{m} 6 \mathrm{~N}$ purity (99.9999\% with respect to metal impurities). Such materials may still contain non-metal contaminants, predominantly oxygen at levels of $100 \mathrm{ppm}$ or higher. Oxide impurities present in crystal growth systems may (i) affect electronic properties of the materials, (ii) increase sticking of the growing crystals to the walls of the container (formation of silicates) leading to detrimental strains in the material, (iii) form excess gas(es) in the system, and (iv) through inclusion may lead to deterioration of crystallographic perfection of the materials.

\footnotetext{
${ }^{*}$ Fax: + 12055448762 ; e-mail: witold palosz(amsfenasa.gov

${ }^{1}$ Universities Space Research Association.
}

High-purity elements are typically obtained by zone refining. Oxides are usually present as insoluble particles, that on zone refining may be retrapped by the solidification interface. Moreover, oxidation of materials may occur during handling of the elements and compounds in air. Therefore. the removal of oxides may be a critical factor in crystal growth and other materials processing. Some material preparation procedures reported in the literature include annealing in hydrogen [1-3] or hydrogen chalcogenides $[4,5]$ atmospheres. In this work, we systematically analyze and discuss physical and thermochemical conditions, and limitations of removal of different oxides (oxygen) of elements important for electronic applications. Theoretical predictions based on thermochemical analysis were verified experimentally. We investigated removal of the metal oxides $\mathrm{Bi}_{2} \mathrm{O}_{3}, \mathrm{CdO}, \mathrm{CuO}$, $\mathrm{Cu}_{2} \mathrm{O}, \mathrm{Ga}_{2} \mathrm{O}_{3}, \mathrm{GeO}, \mathrm{GeO}_{2}, \mathrm{HgO}, \mathrm{In}_{2} \mathrm{O}_{3}, \mathrm{MnO}$. 
$\mathrm{PbO}, \mathrm{Sb}_{2} \mathrm{O}_{3}, \mathrm{SnO}, \mathrm{SnO}_{2}$, and $\mathrm{ZnO}$, and non-metal oxides $\mathrm{As}_{2} \mathrm{O}_{3}, \mathrm{SO}_{2}, \mathrm{SeO}_{2}$, and $\mathrm{TeO}_{2}$. Finally, we discuss the techniques used for the removal of oxides including vacuum evaporation, reduction by hydrogen and carbon (graphite), and volatilization by chalcogens and hydrogen chalcogenides.

\section{General considerations}

\subsection{Mass transport limitations}

The removal of oxides can be accomplished either by a direct vaporization (for simplicity, the term 'vaporization' will be used for vaporization and for sublimation throughout this paper) under (dynamic) vacuum or by a chemical volatilization of the oxide(s) in a flow or sealed system (followed by a vacuum treatment if necessary). Different mass transport (removal) mechanisms may dominate. For low total pressures $\left(P_{\mathrm{t}}<10^{-5}-10^{-6} \mathrm{~atm}\right)$ the mean free path of the gaseous species is larger than the characteristic length of the flow system (the Knudsen number $\mathrm{Kn}>1$ ) and molecular flow ensues. Then the flow rate $r$ (in moles per unit time) can be expressed as

$r=\frac{a_{\mathrm{v}} P S}{\sqrt{2 \pi M R T}}$

(Hertz-Knudsen equation [6]) where $P$ is the (equilibrium) pressure of the component, $M$ its molecular weight, $R$ is the gas constant, $T$ the temperature, $S$ the cross-sectional area of the ampoule, and $a_{v}$ is the vaporization coefficient. For a system with $S=1.76 \mathrm{~cm}^{2}$ (ampoule ID $15 \mathrm{~mm}$ ) and no kinetic limitations for vaporization $\left(a_{v}=1\right)$, the removal of $100 \mathrm{ppm}$ of an oxide from $0.1 \mathrm{~mol}$ of a matrix material in $1 \mathrm{~h}$ (which corresponds to the flow rate of $r=10^{-5} \mathrm{~mol} / \mathrm{h}$ ) requires a vapor pressure of $P \approx 10^{-8}$ atm. In real systems the vaporization coefficient may be less than unity and higher pressures (i.e. temperatures) than those anticipated from Eq. (1) for $a_{\mathrm{y}}=1$ may have to be applied. For flow in a tube, collisions of the molecules with the tube reduce the flow rate by a factor dependent on the tube's length-to-radius ratio [7]. This factor, calculated for our conditions $(L / a=10 / 0.75)$, is 0.154 .
When $\mathrm{Kn}<0.01$ [8], the mass transport is controlled by viscous flow

$$
V=\frac{\pi}{8} \frac{1}{\eta} \frac{\Delta P_{\mathrm{t}}}{\Delta L} a^{4}=\frac{\pi a^{2} R T J}{P_{\mathrm{t}}}
$$

(Hagen-Poiseuille equation [6]) where $V$ is the flow rate (in volume per unit time), $\eta$ is the viscosity, $\Delta P_{1} / \Delta L$ the total pressure gradient along the tube of radius $a$, and $J$ is the molar flux (in moles per unit surface area and time). Integration of Eq. (2) over a distance $L$ where the total pressure $P_{\mathrm{t}}$ drops from $P_{0}$ to $P$ gives

$$
\frac{r}{\pi a^{2}}=J=\frac{a^{2}}{16 R T \eta L}\left(P_{0}^{2}-P^{2}\right) \text {. }
$$

When $P_{0}$ is the pressure over the source and $P=0$, Eq. (3) gives a distillation rate in vacuum. For $P_{0}=10^{-4} \mathrm{~atm}, \quad 2 a=1.5 \mathrm{~cm}, \quad T=1000 \mathrm{~K}, \quad \eta=$ $8 \times 10^{-4} \mathrm{~g} /(\mathrm{cm} \mathrm{s})$, and $L=10 \mathrm{~cm}$, the distillation rate is $r=3.3 \times 10^{-3} \mathrm{~mol}$ per hour. $P_{0}$ may be less than the equilibrium pressure over the source due to kinetic limitations and the mass transport rate may be lower than might be expected from the equilibrium thermodynamic analysis alone.

For $0.01<\mathrm{Kn}<3$ a transitional, very complex mixed flow mode occurs, and theoretical calculations require an elaborate, direct simulation Monte Carlo (DSMC) method [7]. Therefore, for this $\mathrm{Kn}$ range we calculated the extreme mass flow rates determined by Eqs. (1) and (2).

When the oxide is being volatilized chemically (reaction with hydrogen, graphite, chalcogen, or hydrogen chalcogenide), the mass transport rate is limited by diffusion of the reactants through the vapor phase to and from the oxide condensed phase. The reaction products may diffuse out and deposit in a cooler part of the system and can be removed later under dynamic vacuum.

\subsection{Thermochemical limitations}

The rate of oxygen removal depends primarily on the volatility (partial pressures) of the original and related oxides and that of the matrix material. The simplest mechanism is

molecular vaporization

$n \mathrm{~A}_{x} \mathrm{O}_{y}(\mathrm{c})=\mathrm{A}_{n x} \mathrm{O}_{n y}(\mathrm{~g})$ 
or

dissociative vaporization

$\mathrm{A}_{x} \mathrm{O}_{y}(\mathrm{c})=\frac{x}{n} \mathrm{~A}_{n}(\mathrm{c}, \mathrm{g})+\frac{n y-z x}{2 n} \mathrm{O}_{2}(\mathrm{~g})$,

$\mathrm{A}_{x} \mathrm{O}_{y}(\mathrm{c})=\frac{x}{n} \mathrm{~A}_{n} \mathrm{O}_{z}(\mathrm{c}, \mathrm{g})+\frac{n y-z x}{2 n} \mathrm{O}_{2}(\mathrm{~g})$

under vacuum, where ' $c$ ' denotes a condensed phase (solid 's' or liquid 'l'). In the presence of the element, condensed-phase vaporization may proceed through the reaction

$\mathrm{A}_{x} \mathrm{O}_{y}(\mathrm{c})+\frac{n y-z x}{z} \mathrm{~A}(\mathrm{c})=\frac{y}{z} \mathrm{~A}_{n} \mathrm{O}_{z}(\mathrm{~g})$.

The oxide can be removed with only limited loss of the main compound when its partial pressure is about the same or higher than that of the matrix material. When the opposite occurs, an effective separation can be achieved by distillation of the matrix (leaving the less volatile oxide as a residue) but it requires (i) sufficiently high pressure of the distilled component (to make the purification process practical), and (ii) appropriately low pressure of the oxide. (For example, to reduce the amount of an oxide to the level of $1 \mathrm{ppm}$ in the purified material, the pressure of the oxide should be about 6 orders of magnitude lower than that of the matrix.) However, oxides are usually present in the form of finely dispersed solid particles which can be easily carried/drifted along by the gas stream of the molecules or by an accidental electrostatic charge on the ampoule walls, recontaminating the distillation product. This can be minimized by separating the original source material from the purified product with special frits (and higher temperatures to compensate for related reduction in the flow rate). More volatile or less stable oxides of the element should be removed or decomposed first. The vaporization of oxides may be either significantly reduced (Eq. (5a): $\mathrm{Bi}_{2} \mathrm{O}_{3}, \mathrm{ZnO}, \mathrm{CdO}, \mathrm{MnO}, \mathrm{HgO}$ ) or increased (Eq. (6): $\mathrm{Ga}_{2} \mathrm{O}_{3}, \mathrm{In}_{2} \mathrm{O}_{3}, \mathrm{GeO}_{2}, \mathrm{SnO}_{2}$ ) by the presence of a condensed phase of the respective element.

Removal of oxygen by chemical volatilization includes reduction by hydrogen

$\mathrm{A}_{x} \mathrm{O}_{y}(\mathrm{c})+y \mathrm{H}_{2}(\mathrm{~g})=\frac{x}{n} \mathrm{~A}_{n}(\mathrm{c}, \mathrm{g})+y \mathrm{H}_{2} \mathrm{O}(\mathrm{g})$,

reduction by graphite

$$
\begin{aligned}
& \mathrm{A}_{x} \mathrm{O}_{y}(\mathrm{c})+y \mathrm{C}(\mathrm{s})=\frac{x}{n} \mathrm{~A}_{n}(\mathrm{c}, \mathrm{g})+y \mathrm{CO}(\mathrm{g}), \\
& \mathrm{A}_{x} \mathrm{O}_{y}(\mathrm{c})+\frac{y}{2} \mathrm{C}(\mathrm{s})=\frac{x}{n} \mathrm{~A}_{n}(\mathrm{c}, \mathrm{g})+\frac{y}{2} \mathrm{CO}_{2}(\mathrm{~g}),
\end{aligned}
$$

and

formation of metal chalcogenides

$$
\mathrm{A}_{x} \mathrm{O}_{y}(\mathrm{c})+\frac{3 y}{4} \mathrm{~B}_{2}(\mathrm{c}, \mathrm{g})=\mathrm{A}_{x} \mathrm{~B}_{y}(\mathrm{c})+\frac{y}{2} \mathrm{BO}_{2}(\mathrm{c}, \mathrm{g})
$$

$\mathrm{A}_{x} \mathrm{O}_{y}(\mathrm{c})+y \mathrm{H}_{2} \mathrm{~B}(\mathrm{~g})=\mathrm{A}_{x} \mathrm{~B}_{y}(\mathrm{c})+y \mathrm{H}_{2} \mathrm{O}(\mathrm{g})$.

Vapor pressures of the elements were taken from Ref. [9], that of $\mathrm{Sb}_{4} \mathrm{O}_{6}$ from Ref. [10]. We calculated the equilibrium partial pressures for reactions (1)-(5) from the dependence of the equilibrium constants $K$ on the change of the Gibbs function, $\Delta G(\Delta G=-R T \ln K)$ using thermochemical data given in Refs. [11-13]. The equilibrium partial pressures for reactions (5a) and (5b) were computed both for stoichiometric and metal- or telluriumsaturated conditions. The equilibrium partial pressures over sulfur and selenium oxides (reaction (9a)) were calculated for the pressure of the elemental chalcogen of 1 atm or equal to its saturation pressure (for temperatures below the normal boiling point). For tellurides, the sign of the free energy for reaction (9a) (i.e. thermochemical stability of the tellurides) was computed.

\section{Experimental procedures}

The primary focus was on the minimum temperature under which a meaningful purification rate can be achieved. The rate of sublimation under dynamic vacuum (about $10^{-8}$ atm or better) was determined experimentally using $0.5-1.0 \mathrm{mmol}$ of the powder sample (particle size $1-30 \mu \mathrm{m}$ ) placed in silica glass ampoule (ID $15 \mathrm{~mm}$ ). The processing 
time was $0.5-72 \mathrm{~h}$ depending on the rate of vaporization. Not more than $50 \%$ of the initial charge was sublimed in each experiment. The material deposited at a distance of $L=10 \mathrm{~cm}$ from the source. The amount of the deposit was weighted and its composition identified by physicochemical methods.

The reduction of oxides with hydrogen was investigated in silica glass ampoules (ID $20 \mathrm{~mm}$ ) loaded at one end with the powdered oxide, evacuated, and back-filled with 1 atm hydrogen. The end with the oxide sample was placed in a furnace. The water formed by reaction (7) condensed at a distance of $15-20 \mathrm{~cm}$ from the source. In the first series of experiments (with source amount $7 \mathrm{mmol}$ ) the temperature of the sample was gradually increased at a rate of about $400^{\circ} \mathrm{C}$ per hour and the change of the total pressure with temperature was recorded. The initial increase in the pressure due to thermal expansion was followed by a pressure drop (at $T>T_{\mathrm{o}}$ where $T_{\mathrm{o}}$ represents the onset of reduction) due to condensation of water. In the second series of experiments the oxide $(0.8-1.0 \mathrm{mmol})$ was annealed at selected temperature. The rate of reduction was determined from the rate of the pressure decrease with time.

Reduction by graphite was investigated in sealed silica ampoules (ID $15 \mathrm{~mm}$, length $10 \mathrm{~cm}$ ) loaded with $0.8-1 \mathrm{mmol}$ of a given oxide and a necessary amount of graphite. The graphite was in the form of a solid piece, a fine powder, or a thin film deposited on part of the ampoule inner wall prior to loading. The ampoule was sealed under vacuum and annealed. The annealed ampoule was opened under water, the volume of the resulting gas bubble (carbon oxides) measured and the degree of reduction calculated assuming thermochemical equilibrium between $\mathrm{CO}$ and $\mathrm{CO}_{2}$ at the annealing temperature.

Reactions with chalcogens (reaction (9a)) were tested for several oxides: $1 \mathrm{mmol}$ of a given oxide (fine powder) and a stoichiometric amount of the chalcogen were sealed under vacuum in a fused silica ampoule and annealed at a given temperature for $1 \mathrm{~h}$ (longer in several cases, cf. Section 4.1.4, Table 5). The temperature was increased in $100^{\circ} \mathrm{C}$ increments until signs of reaction were noticed. The percentage of the reduced oxide was determined from the amount of unreacted chalcogen in the ampoule.

\section{Results and discussion}

\subsection{Purification rates}

\subsubsection{Sublimation under dynamic vacuum}

Equilibrium partial pressures over the elements and oxides are shown in Fig. 1a-Fig. 1j (the partial pressures of $\mathrm{SnO}, \mathrm{GeO}$, and $\mathrm{PbO}$ include contributions from the multimers $\left.(\mathrm{MeO})_{n}\right)$. Measured and predicted rates of vaporization of the elements and their oxides under dynamic vacuum are summarized in Table 1a and Table $1 \mathrm{~b}$. In most cases the vaporization rates are within a factor of 4 or within the range of our theoretical predictions (cf. Section 2). In some cases kinetic limitations exist, primarily at higher equilibrium pressures (predicted rates $>10 \mathrm{mmol} / \mathrm{h}$ ) and/or lower process temperatures $\left(<500^{\circ} \mathrm{C}\right)$. Relatively low purification rates in two-condensed-phase processes (cf. Eq. (6)) were found to be caused by a limited contact between the phases. Test experiments showed, that an increase in the amount of the source by a factor of ten increases the vaporization rate by less than a factor of two.

\subsubsection{Reduction by hydrogen}

Equilibrium partial pressures of water (Eq. (7)) as a function of temperature calculated for an initial hydrogen pressure $P^{0}\left(\mathrm{H}_{2}\right)=1 \mathrm{~atm}$ are given in Fig. 2. In most cases equilibrium partial pressures of the related elements are low, thus a condensed phase of the element forms and the reduction process does not depend on the initial presence of excess element in the source material. The opposite situation occurs only for $\mathrm{ZnO}$ and $\mathrm{CdO}$ (Fig. 2). Our experimental results are summarized in Table 2 . The rate of reduction at $T_{0}$ is very low, and increases at higher temperatures. The reduction process depends strongly on the grain size of the oxide: reduction rates of the solid chunk and powdered $\mathrm{TeO}_{2}$ differ by more than one order of magnitude (Table 2). The rate decreases as the process progresses and complete reduction requires considerably more time than the initial reduction rates would indicate (Table 2). As expected from our thermochemical calculations (Fig. 2), manganese oxide cannot be reduced by hydrogen under our experimental conditions. The equilibrium partial 

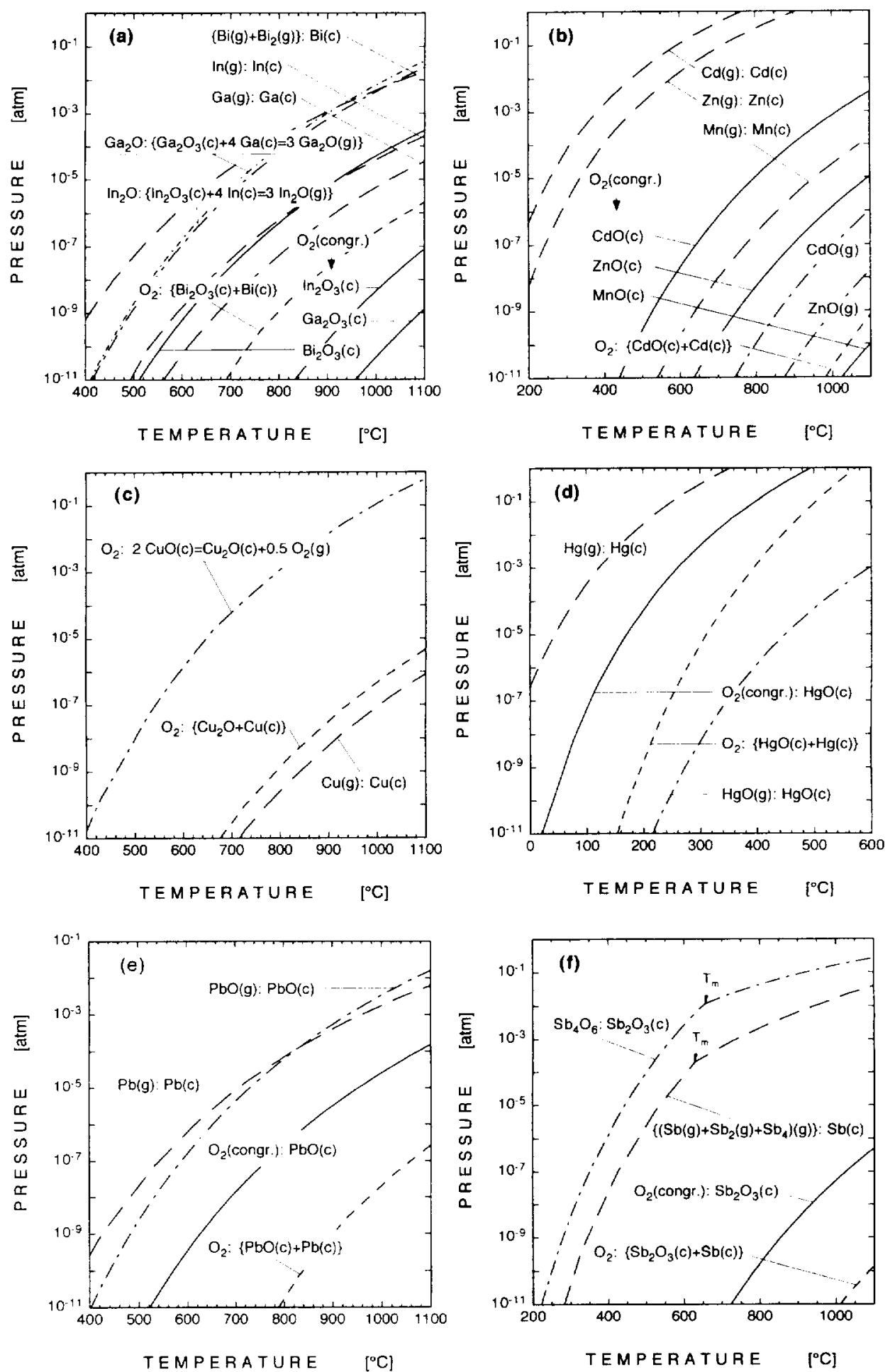

Fig. 1. Equilibrium partial pressures over elements and their oxides. The pressures of oxygen under metal-saturated conditions not shown in the graphs are less than $10^{-11}$ atm. 

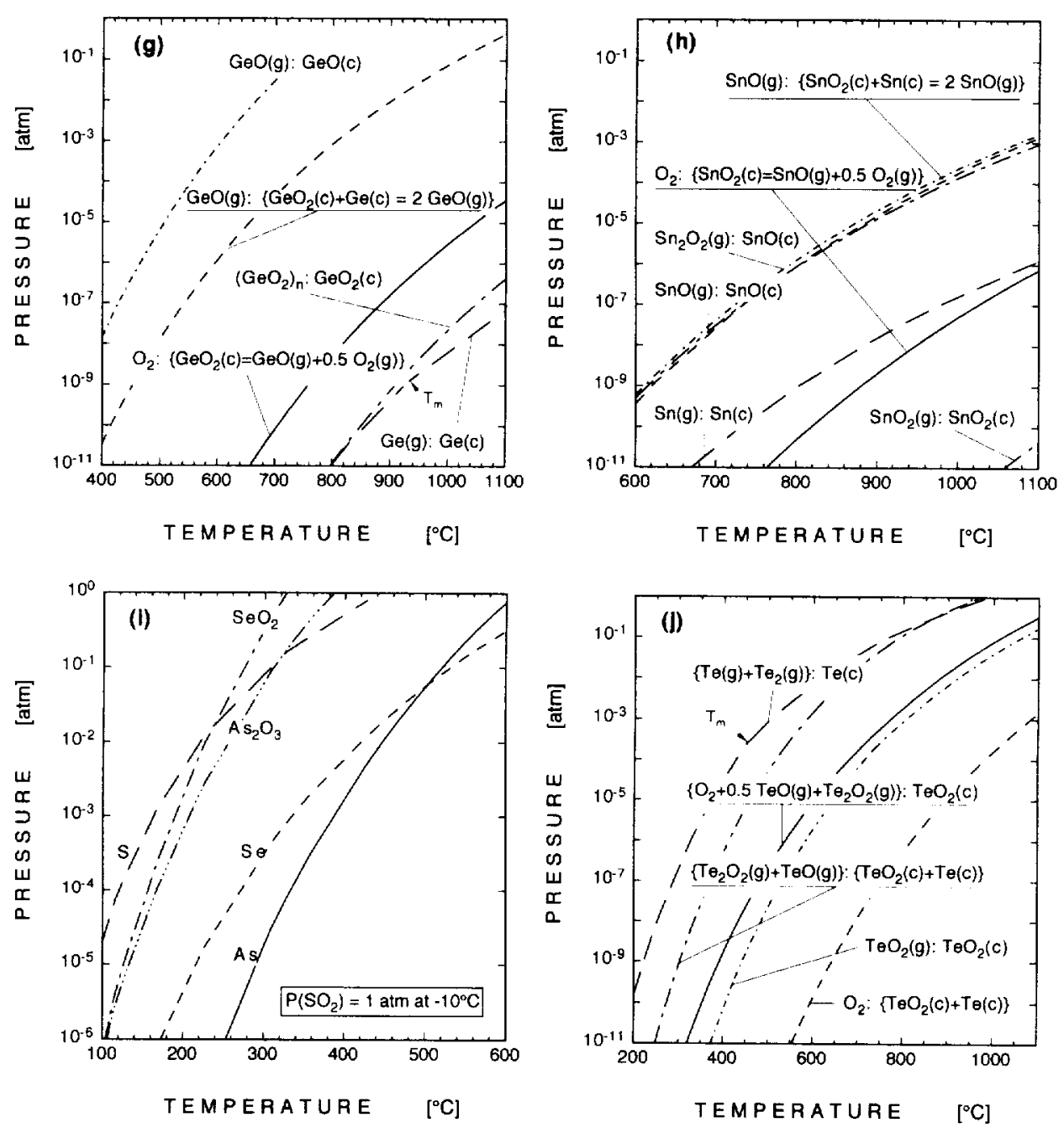

Fig. 1. (Continued).

pressure of water over $\mathrm{Ga}_{2} \mathrm{O}_{3}$ and $\mathrm{ZnO}$ (under congruent vaporization, Fig. 2) is very low. Under these conditions, a chemical vapor transport (CVT) process sets in: the products of the reaction of hydrogen with the oxides are transported to a cooler part of the system where a reversal of the process takes place and the oxide deposits. Reduction of other oxides leads to relatively high $\mathrm{H}_{2} \mathrm{O}$ pressures. Thus, the water is easily removed from the source region and condenses in a cooler part of the system, and a CVT process is practically not observed. The released elements (Eq. (7)) have relatively low vapor pressure under the reduction conditions and (except for $\mathrm{Te}$ ) remain in the source region. They have to be removed (if necessary) in a separate process.

Reduction by hydrogen requires only a small quantity of gas (a few $\mathrm{cm}^{3}$ of hydrogen under normal conditions for $10^{-4} \mathrm{~mol}$ of an oxide), depends on the pressures of $A_{n}$ (or the presence of $A(c)$ ) and hydrogen, and can be usually performed in a closed system. 
Table 1

Vaporization of (a) metal and (b) non-metal oxides under dynamic vacuum; ID $=15 \mathrm{~mm}, \Delta L=10 \mathrm{~cm}, n=0.5-1 \mathrm{mmol}$

\begin{tabular}{lll}
\hline Oxide $T(\mathrm{C})$ & $n i t(\mathrm{mmol} / \mathrm{h})$ & \\
\cline { 2 - 3 } & Theoretical & Experimental \\
\hline
\end{tabular}

(a) Metal oxides

$\begin{array}{ll}\mathrm{Bi} & 750 / 600 \\ \mathrm{Bi}_{2} \mathrm{O}_{3} & 800^{\mathrm{a}} / 700^{+}\end{array}$

$\begin{array}{ll}\mathrm{Bi}_{2} \mathrm{O}_{3} & 800^{\mathrm{a}} / 700^{4} \\ \mathrm{Cd} & 300\end{array}$

$\mathrm{CdO} \quad 900 / 800$

$\mathrm{Cu} \quad 1000$

$\mathrm{Cu}_{2} \mathrm{O} \quad 1000^{\mathrm{a}}$

$\mathrm{Ga} \quad 1000$

$\mathrm{Ga}_{2} \mathrm{O}_{3} \quad 1000$

$\mathrm{Ga}_{2} \mathrm{O}_{3} / \mathrm{Ga} \quad 900 / 800$

Ge 1000

$\mathrm{GeO} \quad 700$

$\mathrm{GeO}_{2} \quad 1000$

$\mathrm{GeO}_{2} / \mathrm{Ge} \quad 930$

$\mathrm{Hg}$

$\mathrm{HgO}$

In

$\ln _{2} \mathrm{O}_{3}$

$\mathrm{In}_{2} \mathrm{O}_{3} / \mathrm{In}$

$\mathrm{Mn}$

$\mathrm{MnO}$

$\mathrm{Pb}$

$\mathrm{PbO}$

$\mathrm{Sb}$

$\mathrm{Sb}_{2} \mathrm{O}_{3}$

$\mathrm{Sn}$

$\mathrm{SnO}$

$\mathrm{SnO}_{2}$

$\mathrm{SnO}_{2} / \mathrm{Sn}$

$\mathrm{Zn}$

$\mathrm{ZnO}$
$195 / 175 / 125 / 110$

$5 1 5 \longdiv { 4 6 0 / 2 1 0 }$

$1000 / 800 / 770$

1000

$900 / 800$

$1000^{\mathrm{a}}$

1000

$800 / 700 / 600$

$800^{c} / 700^{c} / 600^{\alpha} / 500$

$500 / 450$

390

1000

$800 / 700$

1000

$1000 / 760$

$430 / 400$

1000 $2.2\left(1.5 \times 10^{-3}-0.14\right)$
$0.0582 .9 \times 10^{-3} 8.3 \times 10^{-5}$

5-11

(10 23) $(0.12-2.3)$

0.012

0.096

$(0.0150 .80)$

$7.6 \times 10^{-6}$

$434,4.3$

$7.6 \times 10^{-4}$

$>10 \times 10^{4}$

$(0.01-0.7)$

$2 \times 10^{5}$

$4 \times 10^{5} / 1 \times 10^{5} / 3 \times 10^{3 / 750}$

$>70$

$(0.67-4.1) 0.076) 0.037$

$6.1 \times 10^{-4}$

$147,(1.7 \quad 5.4)$

$0.25-3.8$

$1.8 \times 10^{-6}$

$(2.5-6.3) /(0.06-0.9) / 0.063$

(2.3 39) $(0.01-2.7) / 0.015 / 2.6 \times 10^{-4}$

$\left(9 \times 10^{-3} 0.38\right) / 0.043$

$\left(3 \times 10^{-3}-0.055\right)$

0.015

0.270 .01

0.010

19.40 .032

7212

$\left(1.6 \times 10^{-3}-0.31\right)$

$120(3.1-4.4)$

250

(3.6-4.1)

$22(0.013-0.21)$

$24(0.16-0.76)$

$(0.13-1.5) 0.0030 .18)$
3.90 .018

$0.11^{\mathrm{b}} 0.003^{\mathrm{h}}<0.001^{\mathrm{b}}$

$0.61^{\circ}$

$2.0^{c} 0.23$

0.050

0.035

0.14

$<0.0002$

$0.89^{\mathrm{d}} / 0.30^{\mathrm{d}}$

0.002

$>4$

$<0.00003^{\circ}$

$>5^{d}$

$15^{\circ} 3.2^{\circ} 1.8^{\mathrm{c}}: 0.4^{\mathrm{c}}$

$2.6^{\mathrm{c}} 0.42^{\mathrm{c}} 0.013^{\mathrm{c}}$

1.60 .180 .04

$4.2 \times 10^{4}$

$6.5^{\mathrm{d}} 0.65^{\mathrm{d}}$

0.64

$<0.0001$

$3.60 .30 / 0.0004^{\circ}$

$1.540 .38 / 6.2 \times 10^{-3} 5.8 \times 10^{-5}$

$0.14,0.024$

0.059

0.0068

0.240 .041

0.010

$(>0.7)^{\mathrm{d}} 0.020$

$1.0^{\circ} 0.44^{\circ}$

0.0071

(b) Non-metal oxides

$\begin{array}{ll}\mathrm{As} & 345 / 310 \\ \mathrm{~S} & 130 \\ \mathrm{Se} & 240 \\ \mathrm{Te} & 420 / 340 \\ \mathrm{TeO}_{2} & 700 / 600 \\ \mathrm{TeO}_{2} / \mathrm{Te} & 460 / 420\end{array}$

The source reacted with fused silica.

${ }^{b}$ Some of the vaporized material reacted with fused silica.

${ }^{\mathrm{c}}$ Apparent kinetic limitations to vaporization.

Vaporization rate reduced by limited contact between the reacting condensed phases.

'Sublimation performed in alumina tubing. 


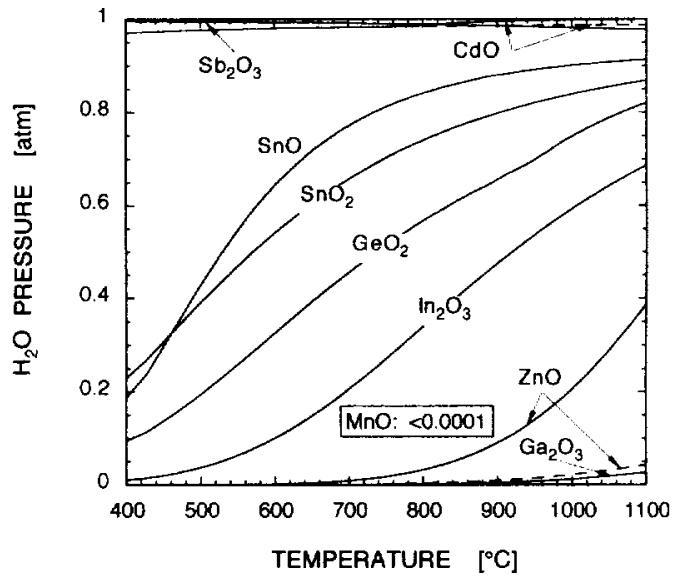

Fig. 2. Vapor pressure of water in equilibrium with oxides. Initial pressure of hydrogen is $P^{0}\left(\mathrm{H}_{2}\right)=1 \mathrm{~atm}$. Solid lines $(-\ldots)$, in the presence of saturated pressure of respective element; dashed lines (- -.- -), under congruent conditions. Equilibrium partial pressures of water in the presence of $\mathrm{PbO}, \mathrm{HgO}$, $\mathrm{TeO}_{2}, \mathrm{Bi}_{2} \mathrm{O}_{3}, \mathrm{Cu}_{2} \mathrm{O}$, and $\mathrm{CuO}$ are more than $0.999 \mathrm{~atm}$.

\subsubsection{Reduction by graphite}

The calculated equilibrium total pressure of $\mathrm{CO}$ and $\mathrm{CO}_{2}$ as a function of temperature (reactions (8a) and $(8 \mathrm{~b})$ ) is plotted in Fig. 3 for various oxides. From these curves one would expect that only $\mathrm{MnO}, \mathrm{ZnO}$ and $\mathrm{Ga}_{2} \mathrm{O}_{3}$ are not significantly reduced below about $700^{\circ} \mathrm{C}$. The experimental results in Table 3 show otherwise. Significant reductions in oxide content required much higher temperatures than anticipated, and $\mathrm{ZnO}, \mathrm{Ga}_{2} \mathrm{O}_{3}$, and $\mathrm{MnO}$ showed no noticeable reduction even after annealing at $1000^{\circ} \mathrm{C}$ for $20-35 \mathrm{~h}$ (Table 3). Apparently, the reactions are kinetically limited at lower temperatures. Furthermore, with intimate mixtures of graphite and oxide powders, the reaction rates were highest. When chunks of graphite were used, the rates dropped. With graphite films, which were physically separated from the oxides, the rates dropped even further. From this it is apparent that the reduction rates were controlled by the mass transport of carbon dioxide from the oxide to the graphite and the corresponding flow of carbon monoxide in the opposite direction (Eq. (8a) and Eq. (8b)). Note that the temperatures required for purification with graphite were typically higher
Table 2

The rate of reduction by hydrogen; initial pressure, $P^{0}\left(\mathrm{H}_{2}\right)$ $=1 \mathrm{~atm}$, amount of the source, $n=0.8-1 \mathrm{mmol} ; T_{0.5}$ and $t_{0.98}$ are the times after which $50 \%$ and $>98 \%$, respectively, of the initial source is reduced. $T_{0}$ is the temperature of the onset of reduction, $(n / t)_{\text {init }}$ is the average reduction rate in the first $10 \mathrm{~min}$ of the process

\begin{tabular}{|c|c|c|c|c|c|}
\hline Oxide & $T_{\mathrm{o}}(\mathrm{C})$ & $T(\mathrm{C})$ & $\begin{array}{l}(n / t)_{\text {init }} \\
(\mathrm{mmol} / \mathrm{h})\end{array}$ & $t_{0.5}(\mathrm{~min})$ & $t_{0.98}(\mathrm{~min})$ \\
\hline $\mathrm{Bi}_{2} \mathrm{O}_{3}$ & 380 & 380 & 0.3 & -10 & 75 \\
\hline \multirow[t]{2}{*}{$\mathrm{CdO}$} & 290 & $\begin{array}{l}400 \\
290\end{array}$ & $<0.3$ & $<10$ & 15 \\
\hline & & 340 & & 30 & 150 \\
\hline \multirow[t]{2}{*}{$\mathrm{Cu}_{2} \mathrm{O}$} & 290 & 300 & 1.0 & & \\
\hline & & 325 & & $<10$ & 75 \\
\hline \multirow[t]{2}{*}{$\mathrm{CuO}$} & 180 & 180 & 1.7 & & \\
\hline & & 220 & 4.3 & & \\
\hline \multirow[t]{2}{*}{$\mathrm{Ga}_{2} \mathrm{O}_{3}$} & a & 900 & 0.06 & & \\
\hline & & 1000 & 0.32 & & \\
\hline \multirow[t]{2}{*}{$\mathrm{GeO}_{2}$} & 590 & 600 & 0.75 & & \\
\hline & & 635 & & 30 & 150 \\
\hline \multirow[t]{2}{*}{$\mathrm{HgO}$} & 290 & 300 & $\leqslant 0.5$ & & \\
\hline & & 350 & & $<5$ & $<30$ \\
\hline \multirow[t]{2}{*}{$\ln _{2} \mathrm{O}_{3}$} & 540 & 540 & 0.15 & & \\
\hline & & 570 & & 40 & 150 \\
\hline $\mathrm{MnO}$ & $>1000$ & .. & - & & \\
\hline \multirow[t]{3}{*}{$\mathrm{PbO}$} & 420 & 420 & $<0.3$ & & \\
\hline & & 450 & 0.75 & & \\
\hline & & 500 & & $<5$ & 30 \\
\hline \multirow[t]{2}{*}{$\mathrm{Sb}_{2} \mathrm{O}_{3}$} & 570 & 570 & 0.3 & & \\
\hline & & 640 & & $<10$ & 90 \\
\hline \multirow[t]{2}{*}{$\mathrm{SnO}$} & 490 & 490 & $<0.3$ & & \\
\hline & & 600 & & 10 & 60 \\
\hline $\mathrm{SnO}_{2}$ & 460 & 460 & $<0.2$ & & \\
\hline \multirow[t]{5}{*}{$\mathrm{TeO}_{2}$} & $560^{\mathrm{b}}$ & 600 & $0.3^{\mathrm{b}}$ & & \\
\hline & & 650 & $0.5^{b}$ & & \\
\hline & 460 & 460 & 0.7 & & \\
\hline & & 560 & 1.9 & & \\
\hline & & 645 & & $<5$ & 60 \\
\hline \multirow[t]{2}{*}{$\mathrm{ZnO}$} & $\mathrm{a}$ & 700 & 0.4 & & \\
\hline & & 770 & 2.0 & & \\
\hline
\end{tabular}

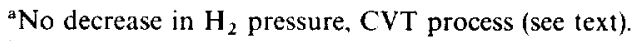

'Solid chunk source.

than those needed for reduction by hydrogen and reaction with chalcogens (see below).

Obviously, removal of oxides by graphite is not an effective purification method. In addition, graphite may be an undesired component which cannot be easily removed from the system. Also, reaction of even trace amounts of graphite and 


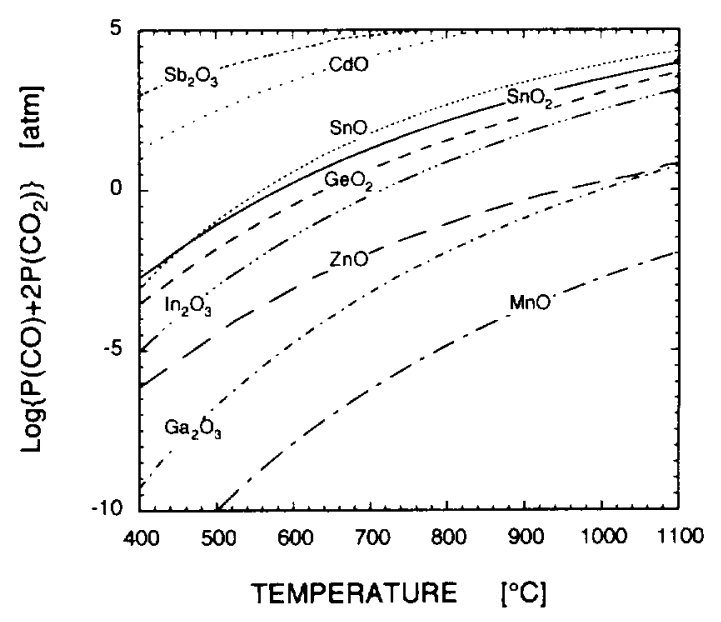

Fig. 3. Equilibrium partial pressures of 'oxygen' $\left(\mathrm{P}(\mathrm{CO})+2 \mathrm{P}\left(\mathrm{CO}_{2}\right)\right)$ in equilibrium with graphite. The total pressure of carbon oxides in the presence of $\mathrm{Bi}_{2} \mathrm{O}_{3}, \mathrm{Cu}_{2} \mathrm{O}, \mathrm{CuO}$, $\mathrm{HgO}, \mathrm{PbO}$, and $\mathrm{TeO}_{2}$ is $\log \left\{P(\mathrm{CO})+2 P\left(\mathrm{CO}_{2}\right)\right\}>5$.

oxide impurity(ies) may affect the amount of residual gas in closed systems and may have a profound effect particularly on PVT processes. In such cases the oxides should be removed before the material is sealed in the growth ampoule. However, it has also been observed that a presence of a piece of graphite in the ampoule during directional solidification of germanium reduces sticking of the material to the silica glass wall [14]. Apparently, the graphite helped in reducing the oxides present in the original source material.

\subsubsection{Removal by chalcogens and hydrogen chalcogenides}

The results of our thermochemical calculations for temperatures up to $1100^{\circ} \mathrm{C}$ (within the range of existence of respective phases) are shown in Table 4. All oxides can be expected to be effectively reduced by sulfur. Selenium and tellurium may reduce only a limited number of oxides (Table 4). Our experimental results are given in Table 5. (The reduction rates are similar when three times larger amounts of the source material are used.) As theoretically predicted, the reactions with the chalcogens proceed already at moderate temperatures $\left(400-500^{\circ} \mathrm{C}\right.$, Table 5). Sulfur and selenium react
Table 3

Oxide reduction rates with graphite

\begin{tabular}{|c|c|c|c|c|}
\hline Oxide & Graphite & $\mathrm{T}(\mathrm{C})$ & Time $(\mathrm{h})$ & $\begin{array}{l}\text { Reduction } \\
(\%)\end{array}$ \\
\hline \multirow[t]{5}{*}{$\mathrm{Bi}_{2} \mathrm{O}_{3}$} & \multirow[t]{4}{*}{$\mathrm{p}$} & 600 & 1 & $<1$ \\
\hline & & 700 & 1 & 40 \\
\hline & & 800 & 1 & 50 \\
\hline & & 900 & 1 & $>80$ \\
\hline & $\mathrm{c}$ & 900 & 1 & 15 \\
\hline \multirow[t]{4}{*}{$\mathrm{CdO}$} & \multirow[t]{2}{*}{$\mathrm{p}$} & 900 & 19 & $<2$ \\
\hline & & 1000 & 1 & $>70$ \\
\hline & \multirow[t]{2}{*}{$\mathrm{c}$} & 1000 & 1 & 30 \\
\hline & & 1000 & 21 & 60 \\
\hline \multirow{3}{*}{$\mathrm{Cu}_{2} \mathrm{O}$} & \multirow[t]{2}{*}{$\mathrm{p}$} & 900 & 2 & $<5$ \\
\hline & & 1000 & 1 & 50 \\
\hline & $f$ & 1000 & 1 & $<2$ \\
\hline $\mathrm{Ga}_{2} \mathrm{O}_{3}$ & $\mathrm{p}$ & 1000 & 35 & $<2$ \\
\hline \multirow[t]{3}{*}{$\mathrm{GeO}_{2}$} & \multirow[t]{2}{*}{$\mathrm{p}$} & 900 & 19 & $<1$ \\
\hline & & 1000 & 1 & 3 \\
\hline & $c$ & 1000 & 21 & 25 \\
\hline \multirow[t]{2}{*}{$\mathrm{HgO}$} & \multirow[t]{2}{*}{$p$} & 500 & 1 & 15 \\
\hline & & 600 & 1 & $>80$ \\
\hline \multirow[t]{3}{*}{$\mathrm{In}_{2} \mathrm{O}_{3}$} & \multirow[t]{3}{*}{$\mathrm{p}$} & 900 & 20 & $<5$ \\
\hline & & 1000 & 1 & 10 \\
\hline & & 1000 & 17 & 30 \\
\hline $\mathrm{MnO}$ & $\mathrm{p}$ & 1000 & 20 & $<1$ \\
\hline \multirow[t]{3}{*}{$\mathrm{PbO}$} & \multirow[t]{2}{*}{$\mathrm{p}$} & 600 & 1 & $<1$ \\
\hline & & 700 & 1 & 30 \\
\hline & $\mathrm{f}$ & 700 & 1 & $<2$ \\
\hline \multirow[t]{3}{*}{$\mathrm{Sb}_{2} \mathrm{O}_{3}$} & \multirow[t]{3}{*}{ p } & 900 & 1 & $<2$ \\
\hline & & 900 & 20 & 25 \\
\hline & & 1000 & 1 & 15 \\
\hline \multirow[t]{2}{*}{$\mathrm{SnO}$} & $\mathrm{p}$ & 800 & 1 & $<2$ \\
\hline & i & 1000 & 1 & 8 \\
\hline \multirow[t]{2}{*}{$\mathrm{TeO}_{2}$} & \multirow[t]{2}{*}{$\mathrm{p}$} & 600 & 1 & 10 \\
\hline & & 700 & 1 & $>80$ \\
\hline $\mathrm{ZnO}$ & $\mathrm{p}$ & 1000 & 35 & $<2$ \\
\hline
\end{tabular}

(p) - powder; (c) - chunk; (f) - film.

more effectively than tellurium, apparently due to their higher volatility relative to that of $\mathrm{Te}$. For $500^{\circ} \mathrm{C}$ and above, the dependence of the reaction rate on temperature is relatively small (Table 5). The annealing time may have only limited effect on the process (Table 5). The weak dependence of the reaction rate on temperature and time suggests that the rate of reduction of the oxides by chalcogens may be limited by diffusion in the solid oxide/chalcogenide particles. 
Table 4

Reduction of oxides by chalcogens; $P\left(\mathrm{SO}_{2}\right)$ and $P\left(\mathrm{SeO}_{2}\right)$ are equilibrium partial pressures (Eq. $\left.(9 \mathrm{a})\right)$ in the presence of the chalcogen condensed phase (below the normal boiling point temperature, $T_{\mathrm{b}}$ ) or under 1 atm of chalcogen (above $T_{b}$ ); $\Delta G$ is the Gibbs energy for reaction of a given oxide with tellurium

\begin{tabular}{llll}
\hline Oxide & $P\left(\mathrm{SO}_{2}+\mathrm{SO}\right)^{\mathrm{a}}$ & $P\left(\mathrm{SeO}_{2}+\mathrm{SeO}\right)^{\mathrm{a}}$ & $\Delta G^{\mathrm{b}}$ \\
\hline $\mathrm{Bi}_{2} \mathrm{O}_{3}$ & + & $\mathrm{c}$ & $>0$ \\
$\mathrm{CdO}$ & + & $>1$ for $T>420 \mathrm{C}$ & $<0$ for $T<580^{\circ} \mathrm{C}$ \\
$\mathrm{Cu}_{2} \mathrm{O}$ & + & + & $<0$ \\
$\mathrm{Ga}_{2} \mathrm{O}_{3}$ & $>1$ for $T>205^{\circ} \mathrm{C}$ & - & $>0$ \\
$\mathrm{GeO}_{2}$ & $>1$ for $T>420^{\circ} \mathrm{C}$ & - & $<0$ \\
$\mathrm{HgO}$ & + & + & $>0$ \\
$\mathrm{In}_{2} \mathrm{O}_{3}$ & $>1$ for $T>180^{\circ} \mathrm{C}$ & - & $>0$ \\
$\mathrm{MnO}_{\mathrm{PbO}}$ & + & - & $<0$ for $T<880^{\prime \prime} \mathrm{C}$ \\
$\mathrm{Sb}_{2} \mathrm{O}_{3}$ & + & $>1$ for $T>400^{\circ} \mathrm{C}$ & $>0$ \\
$\mathrm{SnO}$ & + & - & $>0$ \\
$\mathrm{ZnO}$ & + & - & $>0$ \\
\hline
\end{tabular}

at + ) $P>10$ atm; $(-) P<0.01$ atm.

${ }^{b} \mathrm{Me}_{X} \mathrm{O}_{Y}(\mathrm{c})+1.5 Y \mathrm{Te}(\mathrm{c})=\mathrm{Me}_{X} \mathrm{Te}_{Y}(\mathrm{c})+Y / 2 \mathrm{TeO}_{2}(\mathrm{c})$.

${ }^{\mathrm{c}} P(\max ) \approx 0.09 \mathrm{~atm}$ at $T=685^{\circ} \mathrm{C}$.

Hydrogen chalcogenides (or an appropriate mixture of chalcogen and hydrogen) are more effective reducers than the elemental chalcogens. Our calculations show that the ratio of the equilibrium partial pressure of $\mathrm{H}_{2} \mathrm{O}$ and $\mathrm{H}_{2}$ for reaction $(9 \mathrm{~b})$ is well above unity for all oxides and chalcogenides except for $\mathrm{MnTe}$, where it is between 0.5 and 0.8 (for $T=300-1100^{\circ} \mathrm{C}$ ). Selected test experiments confirmed these predictions: even reduction of $\mathrm{MnO}$ by hydrogen in the presence of tellurium was observed at temperature as low as $600^{\circ} \mathrm{C}$, while a reaction of $\mathrm{MnO}$ with tellurium without hydrogen was not observed even after $20 \mathrm{~h}$ annealing at $1000^{\circ} \mathrm{C}$ (Table 5).

The formation of chalcogenides depends on the pressure of the chalcogen $\left(\mathrm{B}_{2}\right)$ or hydrogen chalcogenide $\left(\mathrm{H}_{2} \mathrm{~B}\right)$ (Eq. (9a) and Eq. (9b), respectively) and can usually be performed in closed ampoules. The process is technically less convenient than purification with $\mathrm{H}_{2}$ but may be useful in some systems.

\subsection{Specific metal oxides}

\subsubsection{Bismuth, gallium, and indium}

The three elements form stable oxides of the formula $\mathrm{Me}_{2} \mathrm{O}_{3}$, which vaporize dissociatively.
Table 5

The rate of reduction of metal oxides by corresponding chalcogens

\begin{tabular}{lccc}
\hline MeX & $T_{\text {ann }}(\mathrm{C})$ & Time $_{\text {ann }}(\mathrm{h})$ & $\begin{array}{c}\text { Percentage of oxide } \\
\text { reduced \% }\end{array}$ \\
\hline $\mathrm{CdSe}$ & 500 & 1 & $>95$ \\
& 500 & 1 & 50 \\
$\mathrm{CdTe}$ & 500 & 4 & 40 \\
& 700 & 1 & 65 \\
$\mathrm{HgTe}$ & 500 & 1 & 50 \\
$\mathrm{MnS}$ & 600 & 1 & 45 \\
& 800 & 2 & 80 \\
$\mathrm{MnTe}$ & 1000 & 15 & $<1$ \\
$\mathrm{PbTe}$ & 500 & 1 & 50 \\
& 500 & 4 & 60 \\
$\mathrm{ZnS}$ & 700 & 1 & 85 \\
& 400 & 1 & 30 \\
& 500 & 1 & 80 \\
& 500 & 4 & $>95$ \\
\hline
\end{tabular}

$\mathrm{BiO}(\mathrm{c})$ and $\mathrm{Bi}_{2} \mathrm{O}_{5}(\mathrm{c})$ decompose to $\mathrm{Bi}_{2} \mathrm{O}_{3}$ below $400^{\circ} \mathrm{C}, \mathrm{In}_{2} \mathrm{O}$ (c) and $\mathrm{Ga}_{2} \mathrm{O}$ (c) vaporize under vacuum at temperatures well below $500^{\circ} \mathrm{C}$. Congruent decomposition pressures are low (Fig. 1a), thus the removal of $\mathrm{Ga}_{2} \mathrm{O}_{3}$ and $\mathrm{In}_{2} \mathrm{O}_{3}$ oxides under dynamic vacuum requires high temperatures and is 
slow. $\mathrm{Bi}_{2} \mathrm{O}_{3}$ requires temperatures at which even the vapors of the oxide react with the fused silica (Table 1a). Rapid removal of $\mathrm{Ga}_{2} \mathrm{O}_{3}$ and $\mathrm{In}_{2} \mathrm{O}_{3}$ occurs in the presence of gallium and indium, respectively (Fig. 1a and Table 1a).

The purification of bismuth by vacuum distillation requires a prior reduction of $\mathrm{Bi}_{2} \mathrm{O}_{3}$. Removal of $\mathrm{Ga}_{2} \mathrm{O}_{3}$ by hydrogen is relatively slow (CVT process, cf. Section 4.1.2) and requires high temperatures (Table 2). The reduction of $\mathrm{Bi}_{2} \mathrm{O}_{3}$ and $\mathrm{In}_{2} \mathrm{O}_{3}$ by $\mathrm{H}_{2}$ proceeds at moderate temperatures (Table 2). The oxides can also react with sulfur and hydrogen chalcogenides (Table 4). A noticeable reduction of $\mathrm{Bi}_{2} \mathrm{O}_{3}$ and $\mathrm{In}_{2} \mathrm{O}_{3}$ by graphite requires higher temperatures $\left(>700^{\circ} \mathrm{C}\right.$ and $>1000^{\circ} \mathrm{C}$, respectively). $\mathrm{Ga}_{2} \mathrm{O}_{3}$ does not show any measurable reduction even after $35 \mathrm{~h}$ annealing at $1000^{\circ} \mathrm{C}$ (Table 3).

\subsubsection{Cadmium, manganese, and zinc}

Stable oxides of the elements have the formula $\mathrm{MeO}$ and vaporize mainly dissociatively (Fig. 1b). $\mathrm{Mn}_{2} \mathrm{O}_{3}, \mathrm{MnO}_{2}, \mathrm{Mn}_{3} \mathrm{O}_{4}$, and $\mathrm{Mn}_{2} \mathrm{O}_{7}$ decompose to $\mathrm{MnO}$ under high vacuum at temperatures well below $1000^{\circ} \mathrm{C}$. $\mathrm{CdO}$ and $\mathrm{ZnO}$ can be removed by congruent vaporization at high temperatures (Fig. $1 \mathrm{~b}$ and Table 1a). The pressure of oxygen under metal-saturated conditions is very low and purification of the metals by vacuum distillation is possible. Reaction of manganese with fused silica at high temperatures may require an alternate vessel material, e.g., alumina. Hydrogen reacts differently with each of the oxides. $\mathrm{CdO}$ gets reduced already around $300^{\circ} \mathrm{C}$. $\mathrm{ZnO}$ is removed by means of a CVT process at elevated temperature. $\mathrm{MnO}$ is not reduced at all. The oxides can be removed by sulfur and hydrogen chalcogenides. $\mathrm{CdO}$ can also be removed by selenium and tellurium (Tables 4 and 5). $\mathrm{CdO}$ is reduced by graphite at $1000^{\circ} \mathrm{C}$, but no apparent reduction of $\mathrm{ZnO}$ and $\mathrm{MnO}$ is observed at that temperature even after a long annealing (Table 3).

\subsubsection{Copper}

There are two copper oxides, $\mathrm{Cu}_{2} \mathrm{O}$ and $\mathrm{CuO}$. $\mathrm{CuO}$ decomposes easily to $\mathrm{Cu}_{2} \mathrm{O}$ which, in turn, decomposes into copper and oxygen (Fig. 1c). The decomposition partial pressures over $\mathrm{Cu}_{2} \mathrm{O}$ are low, and the rate of removal of oxygen requires high temperatures and is slow (Table 1a). The saturation pressure of $\mathrm{Cu}$ is lower than that for stoichiometric dissociative vaporization of $\mathrm{Cu}_{2} \mathrm{O}$ and $\mathrm{Cu}(\mathrm{c})$ phase forms in the source region. Condensing copper gets 'fused' into silica in the deposition zone apparently by a process of diffusion into the solid. The equilibrium pressure over $\mathrm{Cu}(\mathrm{c})$ is too low for an effective purification by vacuum distillation under practical laboratory conditions. Removal of the oxides by hydrogen, chalcogens, hydrogen chalcogenides, and graphite is feasible and can be accomplished at relatively low temperatures (Tables $2-4$ and Figs. 2 and 3).

\subsubsection{Mercurv}

Of the two oxides, $\mathrm{Hg}_{2} \mathrm{O}$ decomposes at $100^{\circ} \mathrm{C}$. $\mathrm{HgO}$ vaporizes primarily dissociatively (Fig. 1d) and can be removed below $400^{\circ} \mathrm{C}$. The vaporization rate of $\mathrm{Hg}$ (Table $1 \mathrm{a}$ ) is much lower than expected from equilibrium partial pressures shown in Fig. 1d. The partial pressure of oxygen is not sufficiently low for an effective direct purification of mercury by vacuum distillation, thus a prior reduction of the oxide (by hydrogen) may be necessary. Removal of oxygen by hydrogen, chalcogens, hydrogen chalcogenides, and graphite is feasible (Tables 2-4 and Figs. 2 and 3).

\subsubsection{Lead}

The most stable lead oxide is $\mathrm{PbO}\left(\mathrm{Pb}_{2} \mathrm{O}, \mathrm{Pb}_{2} \mathrm{O}_{3}\right.$ $\mathrm{PbO}_{2}$, and $\mathrm{Pb}_{3} \mathrm{O}_{4}$ decompose to $\mathrm{PbO}$ below $400^{\circ} \mathrm{C}$ under vacuum). This oxide vaporizes primarily molecularly (Fig. 1e). Removal of oxygen should occur mainly through $\mathrm{PbO}$ species and at moderate temperatures (Fig. 1e). However, our experiments showed that the vaporization occurs largely through dissociation of $\mathrm{PbO}$ (deposition of $\mathrm{Pb}(\mathrm{c})$ ) and at vaporization rates consistent with the congruent dissociation pressure of $\mathrm{PbO}$. Lead oxide reacts easily with fused silica at temperatures as low as $600^{\circ} \mathrm{C}$ (Table 1a). Thus, an alternate to fused silica material may be required for the purification vessel. Vacuum distillation of $\mathrm{Pb}$ may require a prior reduction of $\mathrm{PbO}$ with hydrogen. Removal of oxygen by hydrogen, chalcogens, hydrogen chalcogenides, and graphite is feasible (Tables $2-4$ and Figs. 2 and 3 ). 


\subsubsection{Antimony}

The stable oxide is $\mathrm{Sb}_{2} \mathrm{O}_{3}\left(\mathrm{SbO}_{2}\right.$ and $\mathrm{Sb}_{2} \mathrm{O}_{5}$ decompose to $\mathrm{Sb}_{2} \mathrm{O}_{3}$ below $800^{\circ} \mathrm{C}$ ). This oxide vaporizes molecularly in the form of $\mathrm{Sb}_{4} \mathrm{O}_{6}$ species [10] and can be easily removed under vacuum at temperatures as low as $400^{\circ} \mathrm{C}$ (Fig. If and Table 1a). Removal of oxygen by hydrogen, sulfur, hydrogen chalcogenides, and graphite is possible (Tables 2-4 and Figs. 2 and 3).

\subsubsection{Germanium}

Germanium monoxide, $\mathrm{GeO}$, is relatively volatile and vaporizes molecularly (Fig. $1 \mathrm{~g}$ ). However, the congruent sublimation of $\mathrm{GeO}_{2}$ requires high temperatures and is very slow (Table 1a), apparently due to some kinetic limitations. Much faster vaporization can be obtained in the presence of $\mathrm{Ge}$ condensed phase (Fig. 1g and Table 1a). The partial pressure of germanium is very low, and vacuum distillation is not feasible. Removal of $\mathrm{GeO}_{2}$ (and $\mathrm{GeO}$ ) by hydrogen, sulfur, hydrogen chalcogenides, and graphite is possible (Tables $2-4$ and Figs. 2 and 3).

\subsubsection{Tin}

Similar to germanium, tin forms two oxides: more volatile $\mathrm{SnO}$ and much less volatile $\mathrm{SnO}_{2}$ (Fig. 1h). Removal of $\mathrm{SnO}$ is fast, that of $\mathrm{SnO}_{2}$ is much slower (Fig. $1 \mathrm{~h}$ and Table 1a). Removal of $\mathrm{SnO}_{2}$ (c) is facilitated by the presence of Sn condensed phase (Fig. 1h and Table 1a). Saturation pressure of tin is low and vacuum distillation is very slow. The oxides can be removed by hydrogen, sulfur, hydrogen sulphide, and graphite (Tables $2-4$ and Figs. 2 and 3).

\subsection{Specific non-metal oxides}

Equilibrium partial pressures over chalcogens and arsenic and their most stable oxides are shown in Fig. 1i and Fig. 1j. Except for $\mathrm{TeO}_{2}$, the oxides vaporize molecularly and are more volatile (normal boiling point below $400^{\circ} \mathrm{C}$ ) than the respective elements (Fig. 1i). The oxides can usually be removed simultaneously with removal of metal oxides from compound materials. Purification of S, Se, and As can easily be achieved by vacuum annealing or distillation (Table 1b).
Partial pressures over congruent $\mathrm{TeO}_{2}(\mathrm{c})(\mathrm{TeO}$, $\mathrm{Te}_{2} \mathrm{O}_{2}, \mathrm{O}_{2}$, and $\mathrm{TeO}_{2}$ species) are lower than that of elemental tellurium (Fig. 1j) (TeO(c) and $\mathrm{TeO}_{3}$ (c) decompose below $400^{\circ} \mathrm{C}$ ). Therefore, an effective removal of oxygen may require reduction of $\mathrm{TeO}_{2}$ by hydrogen. The presence of $\mathrm{Te}(\mathrm{c})$ should increase the equilibrium pressures over $\mathrm{TeO}_{2}$ (c) (Fig. 1j). However, our tests did not show any noticeable effect of $\mathrm{Te}(\mathrm{c})$ on removal of $\mathrm{TeO}_{2}$ (Table $1 \mathrm{~b}$ ), apparently due to some kinetic limitations under our experimental conditions.

\section{Summary}

The removal of oxides from materials can be accomplished using different physical and/or chemical processes and procedures. This paper illustrates the potentials and limitations of several basic techniques that can be used for that purpose in research laboratories and industrial technological processes. Real experimental conditions may differ from those used in this work and each specific system should be critically assessed. For example, oxide impurities in source elements and compounds are usually present in a finely dispersed form and their removal may proceed more rapidly than under our experimental conditions. On the other hand, vaporization rates may be lower when only a very small amount of the oxide is present (left) in the system. The rate of the purification process may also be reduced if the oxide is trapped inside a solid matrix material grain. Therefore, powdered solid materials should be used. Also, this work addresses only the direct removal of oxides (oxygen) from the related element (e.g. removal of $\mathrm{Bi}_{2} \mathrm{O}_{3} / \mathrm{O}_{2}$ from liquid/solid bismuth). Removal of a given oxide from an unrelated element or compound (e.g. $\mathrm{ZnO}$ in liquid/solid cadmium or cadmium telluride) requires additional considerations. These concern, primarily, the volatility and chemical reactivity of the material with respect to the oxide; for example, a less stable oxide may form a more stable one in reaction with the matrix compound.

Purification by vacuum annealing is a subject to specific thermochemical (low pressure(s)), kinetic, and geometrical limitations to mass flow. Therefore, removal of oxides by active gaseous species 
(hydrogen, chalcogen, hydrogen chalcogenide) can be recommended.

The main objective of our work was to determine borderline conditions required for a given process. In many cases other process parameters (e.g. higher temperature) can be used and the purification process can proceed faster than reported in this work.

\section{Acknowledgements}

The support of this work by the Microgravity Science and Applications Division of the National Aeronautics and Space Administration (grant NAG8-1139) is gratefully acknowledged.

\section{References}

[1] E. Kaldis, I. Phys. Chem. Solids 26 (1965) 1701

[2] K.W. Benz and G. Müller, J. Crystal Growth 46 (1979) 35.
[3] W. Palosz, K. Grasza, D. Gillies and G. Jerman, J. Crystal Growth 169 (1996) 20

[4] E. Kaldis, J. Crystal Growth 5 (1969) 376.

[5] W. Palosz, J. Crystal Growth 61 (1983) 412.

[6] E. Kaldis, in: Crystal Growth, Theory and Techniques, Vol. 1. Ed. C.H.L. Goodman (Plenum, New York, 1974).

[7] G.A. Bird, Molecular Gas Dynamics and the Direct Simulation of Gas Flows, (Clarendon. Oxford, 1994).

[8] S.A. Schaaf and P.L. Chambre, Flow of Rarefied Gases, (Princeton University Press, Princeton, 1961).

[9] R. Hultgren, Ed., Selected Values of the Thermodynamic Properties of the Elements (American Society for Metals. 1973).

[10] G.V. Samsonov, Ed., The Oxide Handbook (Plenum, New York. 1982)

[11] R.H. Lamoreaux, D.L. Hildenbrand and L. Brewer, J. Phys. Chem. Ref. Data 16 (1987) 419

[12] I. Barin and O. Knacke, Thermochemical Properties of Inorganic Substances (Springer, Berlin, 1974).

[13] I. Barin, O. Knacke and I. Kubaschewski. Thermochemical Properties of Inorganic Substances. Supplement (Springer, Berlin, 1977).

[14] F.R. Szofran, private communication. 



\title{
Journal of Crystal Growth
}

\author{
Instructions to Authors (short version)
}

\begin{abstract}
Submission of papers
Manuscripts (one original + two copies), should be sent to a member of the Editorial Board or preferably to an appropriate subject Associate Editor. News or announcements should be submitted through the Principal Editor; a duplicate should be sent directly to Elsevier Science B.V., address given below. Original material. Submission of a manuscript implies it is not being simultaneously considered for publication clsewhere and that the authors have obtained the necessary authority for publication.
\end{abstract}

\section{Types of contributions}

Original research papers, Letters to the Editors and Priority communications are welcome. They should contain an Abstract (of up to 200 words) and a Conclusion section, which particularly in the case of theoretical papers translates the results into terms readily accessible to most readers.

As a guideline: experimental papers should not be longer than 16 double-spaced typed pages, and 8 figures + tables; for theoretical papers a maximum of 20 pages and 10 figures + tables is suggested.

Letters and Priority communications should not be longer than 5 double-spaced typed pages, and 3 figures + tables. They will be given priority in both the refereeing and production processes. The faster production schedule may preclude sending proofs of Letters and Priority communications to authors.

\section{Manuscript preparation}

Contributions may be written in English, French or German. They should have an abstract in English. The paper copies of the text should be prepared with double line spacing and wide margins, on numbered sheets.

Structure. Please adhere to the following order of presentation: Article title, Author(s), Affiliation(s), Abstract, PACS codes and keywords, Main text, Acknowledgements, Appendices, References, Figure captions, Tables.

Corresponding author. The name, complete postal address, telephone and fax numbers and the e-mail address of the corresponding author should be given on the first page of the manuscript.

Classification codes/keywords. Please supply one to four classification codes (PACS and/or MSC) and up to six keywords of your own choice that describe the content of your article in more detail.

References. References to other work should be consecutively numbered in the text using square brackets and listed by number in the Reference list. Please refer to the more detailed instructions for examples

\section{Illustrations}

Illustrations should also be submitted in triplicate: one master set and two sets of copies. The line drawings in the master set should be original laser printer or plotter output or drawn in black india ink, with careful lettering, large enough ( $35 \mathrm{~mm}$ ) to remain legible after reduction for printing. The photographs should be originals, with somewhat more contrast than is required in the printed version. They should be unmounted unless part of a composite figure. Any scale markers should be inserted on the photograph itself, not drawn below it.
Colour plates. Figures may be published in colour, if this is judged essential by the Editor. The Publisher and the author will each bear part of the extra costs involved. Further information is available from the Publisher.

\section{After acceptance}

Important. When page proofs of the accepted manuscripts are made and sent out to authors, this is in order to check that no undetected errors have arisen in the typesetting (or file conversion) process. At the proof stage only printer's errors may be corrected. No changes in, or additions to, the edited manuscript will be accepted.

Notification. The authors will receive the final answer of acceptance or rejection from the Office of the Principal Editor and will be invited to supply an electronic version of the accepted text, if this is not already available.

Copyright transfer. In the course of the production process you will be asked to transfer the copyright of the article to the Publisher. This transfer will ensure the widest possible dissemination of information.

\section{Electronic manuscripts}

The Publisher welcomes the receipt of an electronic version of your accepted manuscript. If there is not already a copy of this (on diskette) with the journal editor at the time the manuscript is being refereed, you will be asked to send a file with the text of the accepted manuscript directly to the Publisher by e-mail or on diskette (allowed formats $3.5^{\prime \prime}$ or 5.25" MS-DOS, or 3.5" Macintosh) to the address given below. (When e-mailing a non-ASCII word-processor file, you should encode it, e.g. with UUENCODE or BinHex, so as to retain all formatting codes.) The name and version of the word-processing program and the type of operating system should always be indicated. Please note that no deviations from the version accepted by the Editor of the journal are permissible without the prior and explicit approval by the Editor. Such changes should be clearly indicated on an accompanying printout of the file

\section{Author benefits}

No page charges. Publishing in Journal of Crystal Growth is free.

Free offprints. The corresponding author will receive 50 offprints free of charge. An offprint order form will be supplied by the Publisher for ordering any additional paid offprints. Discount. Contributors to Elsevier Science journals are entitled to a $30 \%$ discount on all Elsevier Science books.

\section{Further information (after acceptance)}

Elsevier Science B.V., J. Crystal Growth
Issue Management Physics
and Materials Science
P.O. Box 2759.1000 CT Amsterdam
The Netherlands
Fax: + $31204852319+31204852704$
E-mail: matsci-de-f(ajelsevier.nl

Elsevier Science B.V., J. Crystal Growth Issue Management Physics

The Netherland

E-mail: matsci-de-f(a)elsevier.nl 
